\title{
ESTIMATION OF BIOPHYSICAL PARAMETERS OF WHEAT CROP THROUGH MODIFIED WATER CLOUD MODEL USING SATELLITE DATA
}

\author{
Vijay Pratap Yadav ${ }^{1,}$, Rajendra Prasad ${ }^{1}$, Ruchi Bala ${ }^{1}$, A. K. Vishwakarma ${ }^{1}$, S. A. Yadav ${ }^{1}$ \\ ${ }^{1}$ Department of Physics, Indian Institute of Technology (BHU), Varanasi (victory327759@gmail.com, rprasad.app@itbhu.ac.in, \\ ruchibala7@gmail.com, ajeetbhu87@gmail.com,yadavsuraja.rs.phy17@itbhu.ac.in)
}

Commission V, SS: Natural Resources Management

KEY WORDS: Modified WCM, Leaf Area Index, LWAI, Sentinel-1A, Landsat-8

\begin{abstract}
:
A modified water cloud model (WCM) was used to estimate the biophysical parameters of wheat crop using Sentinel - 1A and Landsat - 8 satellite images. The approach of combining the potential of SAR and optical data provided a new technique for the estimation of biophysical parameters of wheat crop. The biophysical parameters estimation was done using non-linear least squares optimization technique by minimizing the cost function between the backscattering coefficients $\left(\sigma^{0}\right)$ computed from the Sentinel-1A image and simulated by the modified WCM followed by look up table algorithm(LUT). The modified WCM integrates the full account of backscattering response on vegetation and bare soil by adding vegetation fraction. The modified WCM was found more sensitive than the original WCM because of incorporation of vegetation fraction $\left(f_{\text {veg }}\right)$ derived from the Landsat-8 satellite data. The estimated values of leaf area index (LAI) by modified WCM at VV polarization shows good correlation $\left(\mathrm{R}^{2}=83.08 \%\right.$ and $\left.\mathrm{RMSE}=0.502 \mathrm{~m}^{2} / \mathrm{m}^{2}\right)$ with the observed values. Whereas, leaf water area index (LWAI) shows comparatively poor correspondence $\left(\mathrm{R}^{2}=76 \%\right.$ and $\left.\mathrm{RMSE}=0.560 \mathrm{~m}^{2} / \mathrm{m}^{2}\right)$ with the observed data in comparison to LAI estimation at VV polarization. The performance indices show that the modified WCM was found more accurate for the estimation of wheat crop parameters during the whole growth season in Varanasi district, India. Thus, the modified WCM shows significant potential for the accurate estimation of LAI and LWAI of wheat crop on incorporating both SAR and optical satellite data.
\end{abstract}

\section{INTRODUCTION}

Earth surface vegetation parameters have been identified as the most important physical properties of terrestrial surfaces due to their specific roles in atmosphere interactions and climate change studies. This parameter regulates the energy exchanges between the earthatmosphere interfaces, and dominates the functioning of hydrological processes through modification of interception, infiltration, and its effects on surface albedo, roughness and evapotranspiration etc. (Beer, C. et al. 2010, Raich, J.W. et al. 1992).

Vegetation monitoring can be achieved through the evaluation of their biophysical parameters such as leaf area index (LAI), leaf water area index (LWAI) and vegetation water content (VWC) etc. Nowadays, the availability of the fine spatial and temporal satellite data has helped in the time series analysis of crop growth and their seasonal activities accurately. Remote sensing satellites have great potential for continuous monitoring of the earth surfaces for the purpose of biophysical parameters estimation of crops at regional/global scale, which plays a vital role in improving regional and global climate models, crop yields modeling and investigating eco-environment.

\footnotetext{
${ }^{*}$ Corresponding author
}

Several empirical and physical models have been developed to describe the relationship between radar backscattering and biophysical parameters for various crops. Ulaby and Attema (1978), has proposed water cloud model (WCM), which describes the relationship between backscattering and vegetation parameters. WCM considers only the single scattering from ground and vegetation slab. It does not include the multiple scattering from the vegetation- soil layers.

The WCM has been updated several times to improve the retrieval accuracy of biophysical parameters. For example, Ulaby et al. 1984 introduced the volume canopy moisture or the LAI in the model. Prevot et al. 1993 modified the input parameters of the WCM using their experimental data. Kumar et al. 2012 estimated the model parameter A and $\mathrm{B}$ using the GA technique and compared those constants with the values estimated by minimization technique. Soon-Koo Kweon et al. 2015 modified the WCM by incorporating new factor like leaf angle distribution of canopy to estimate the backscattering coefficients accurately. Yang et al. 2016 estimated rice variables using improved modified WCM by incorporating different scattering layers of crop at phenological stages 
and the GA optimization techniques were used for parameterization of the model. Liangling et al. 2016 proposed the modified WCM using vegetation fraction and integral equation model (IEM) to retrieve the LAI using Cband RADARSAT-2 and Landsat- 8 satellite data. The modified model predicted the LAI values precisely with high $\mathrm{R}^{2}(84.1 \%)$ and low root mean square error $(\mathrm{RMSE}=$ $\left.0.233 \mathrm{~m}^{2} / \mathrm{m}^{2}\right)$.

In this context, a modified WCM was used to estimate the LAI and LWAI of wheat crop using C-band Sentinel-1A and Landsat-8 satellite data along with in-situ measurement. The backscattering and biophysical parameters of wheat canopy at different crop growth stages and soil moisture variability were used to evaluate the inversion potential for the estimation of LAI and LWAI using non-linear least square optimization technique followed by LUT algorithm.

\section{STUDY AREA AND DATA USED}

\subsection{Study area}

A part of Varanasi district, Uttar Pradesh, India, was chosen for the estimation of crop parameters using proposed methodology in the present study. The study area lies at an average height of $81 \mathrm{~m}$ above the mean sea level and center latitude $25^{\circ} 17^{\prime} 51^{\prime \prime} \mathrm{N}$ and longitude $82^{\circ} 56^{\prime} 36^{\prime \prime}$ E covering a total area of $192 \mathrm{~km}^{2}$. It is one of the holy cities in India located near the holy river Ganges. A moist subtropical climate with seasonal variations between winter and summer temperatures is found in Varanasi. For agriculture purpose this region is very fertile and wealthy natural condition because of its location in Indo-Gangetic plane, as shown in Figure 1.

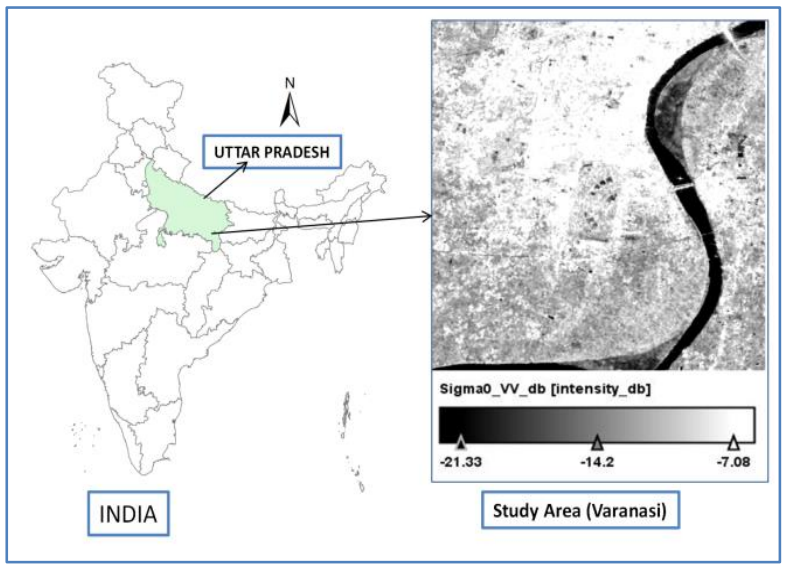

Figure 1. Location of study area with Sentinel-1A image (02 February 2017)

\subsection{Satellite data}

The Sentinel $-1 \mathrm{~A}$ and Landsat -8 satellite images were acquired on February 02 and March 25 in the present study. The central frequency of the SAR sensor is $5.405 \mathrm{GHz}(\mathrm{C}$ band). The image preprocessing was achieved in SNAP tools with radiometric calibration and terrain correction. An enhanced Lee filter was carried out to reduce the speckle noise. The SAR intensity image was converted to $\mathrm{dB}$ from linear scale. The Landsat- 8 optical images were used in this context with a spatial resolution of $30 \mathrm{~m}$. The radiometric calibration and atmospheric correction were performed using ENVI -5.1. At last, the image was geometrically corrected according to Sentinel-1A. The details specification of satellite data is summarized in Table 1.

\begin{tabular}{|c|c|c|c|c|}
\hline \multicolumn{5}{|c|}{ A). SAR (Synthetic Aperture Radar) data. } \\
\hline Satellite & $\begin{array}{c}\text { Date of } \\
\text { Acquisition }\end{array}$ & $\begin{array}{c}\text { Polarizat } \\
\text {-ion }\end{array}$ & $\begin{array}{c}\text { Product } \\
\text { type }\end{array}$ & $\begin{array}{c}\text { Resolution } \\
\text { (m X m) }\end{array}$ \\
\hline $\begin{array}{c}\text { Sentinel-1A } \\
\text { (C-band) }\end{array}$ & $02 / 02 / 2017$ & VV/VH & GRD & 5 X 20 \\
\cline { 2 - 6 } & $25 / 03 / 2017$ & VV/VH & GRD & 5 X 20 \\
\hline \multirow{2}{*}{ B). Optical data } & $\begin{array}{c}\text { Date of } \\
\text { Satellite }\end{array}$ & $\begin{array}{c}\text { No. } \\
\text { of } \\
\text { bands }\end{array}$ & $\begin{array}{c}\text { Spatial } \\
\text { resolution } \\
\text { (m) }\end{array}$ & $\begin{array}{c}\text { Radiometric } \\
\text { resolution }\end{array}$ \\
\hline \multirow{2}{*}{ Landsat-8 } & $02 / 02 / 2017$ & 11 & 30 & 12 bit \\
\cline { 2 - 6 } & $25 / 03 / 2017$ & 11 & 30 & 12 bit \\
\hline
\end{tabular}

Table 1.SAR and Optical satellite data specifications

\subsection{Field data collection}

Agricultural area under the study was mostly covered by wheat crop. The biophysical parameters of this crop like LAI was measured by using LAI-2200C plant canopy analyzer (LI-COR. Inc.). The soil samples were taken from the depth of $5 \mathrm{~cm}$ of soil surface at different locations within the study area (Bruckler et al. 1988, Morvan et al. 2008, Kumar et al. 2018). The details of ground truth measurement are shown in Table 2. 


\begin{tabular}{|c|c|c|c|}
\hline Date & $\begin{array}{c}\text { LAI } \\
\left(\mathrm{m}^{2} / \mathrm{m}^{2}\right) \\
(\mathrm{min}-\mathrm{max})\end{array}$ & $\begin{array}{c}\text { Soil moisture } \\
(\%) \\
(\min -\max )\end{array}$ & $\begin{array}{c}\text { Sampling } \\
\text { point }\end{array}$ \\
\hline $02 / 02 / 2017$ & $0.87-5.2$ & $4.8-38.4$ & 36 \\
\hline $25 / 03 / 2017$ & $1.14-5.6$ & $7.8-44.2$ & 43 \\
\hline
\end{tabular}

Table 2.Field measurements of wheat crop

\section{METHODOLOGY}

The methodology for the estimation of biophysical parameters of wheat crop through modified WCM is shown in Figure 2.

\subsection{Modified water cloud model (WCM)}

WCM considered as homogeneous anisotropic scattering from vegetation and soil layers. It doesn't include the multiple scattering mechanisms between vegetation and soil surface. It is a semi-empirical model based on scattering mechanism between vegetation-soil interfaces. The major specification of this model is the inversion approach, which can be used efficiently in operational techniques. However, further modification and calibration efforts are needed for different crops and region.

The modified WCM is expressed as

$\sigma^{0}(d B)=f_{v e g} A V_{1}^{E} \cos \theta\left[1-\exp \left(\frac{-2 B V_{2}}{\cos \theta}\right)\right]+\left(1-f_{v e g}\right)\left(C+D m_{S}\right) \exp \left(\frac{-2 B V_{2}}{\cos \theta}\right)$

Whereas $\theta$ is incidence angle and $f_{\text {veg }}$ is the vegetation fraction which can be calculated from Landsat- 8 satellite data using equation (2).

$$
f_{\text {veg }}=\frac{N D V I-N D V I_{\min }}{N D V I_{\max }-N D V I_{\min }}
$$

Where NDVI is the normalized differential vegetation index. $\mathrm{NDVI}_{\max }$ and $\mathrm{NDVI}_{\min }$ were computed from the Landsat- 8 satellite data.

In equation (1), the vegetation descriptors $\mathrm{V}_{1}$ and $\mathrm{V}_{2}$ can be LAI or LWAI depending on the consideration for its estimation (Dabrowska-Zielinska et al. 2007). The LWAI is the product of LAI and $W$ (amount of water) as expressed by equation (3)

$$
\text { LWAI }=\text { LAI. } W
$$

where $W$ was computed by using equation (4).

$$
W=\frac{w_{w}-w_{d}}{w_{d}}
$$

Where $w_{w}$ is fresh vegetation sample and $w_{d}$ is dry vegetation samples of wheat crop.

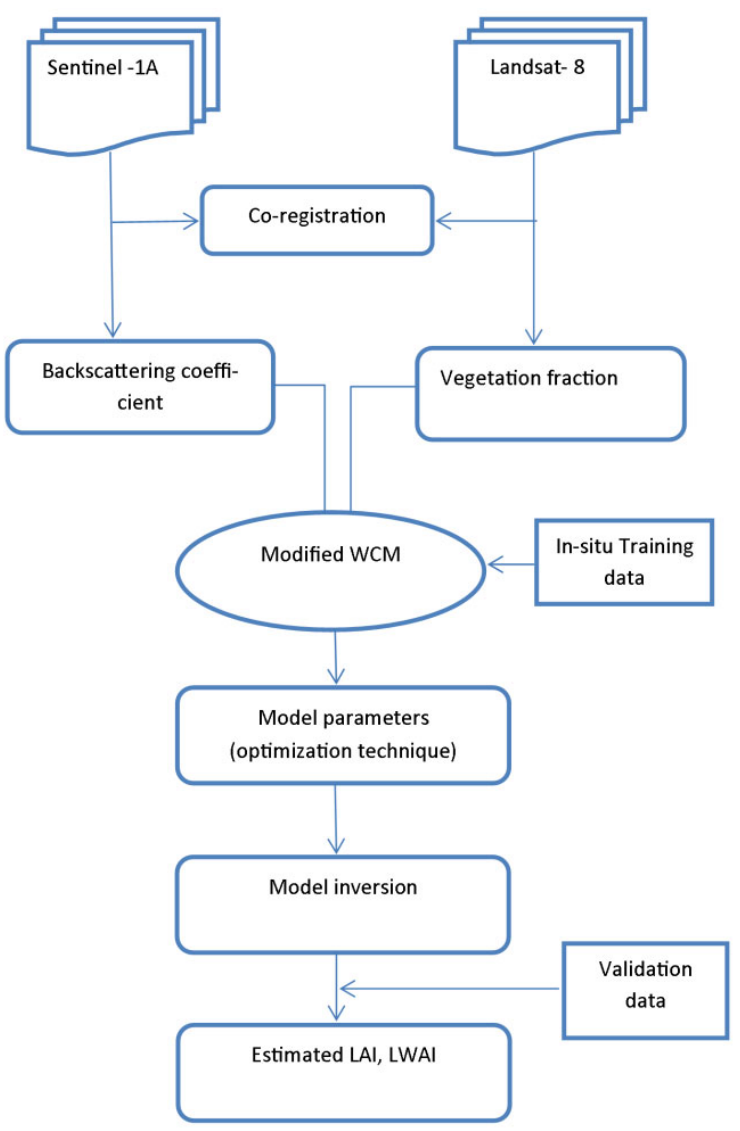

Figure 2.Flow chart of methodology for the present study

\subsection{Model creation and modified WCM parameters estimation.}

The inversion technique was established to estimate the LAI and LWAI based on sentinel $-1 \mathrm{~A}$ data and ground truth data. In equation (1), model parameters A, E, B, C and $D$ were unknown parameters, while other crop growth parameters were observed values. The model parameters were determined by minimization of root mean square error (RMSE) between the observed and simulated $\sigma^{0}(\mathrm{~dB})$ using nonlinear least square optimization algorithm (Prasad R. 2011, Kumar et al. 2015).

$$
\operatorname{RMSE}=\sqrt{\frac{\sum_{\mathrm{i}=1}^{\mathrm{n}}\left(\sigma 0_{\mathrm{ob}}-\sigma 0_{\mathrm{mod}}\right)^{2}}{\mathrm{~N}}}
$$

where $\sigma 0_{\mathrm{ob}}$ and $\sigma 0_{\mathrm{mod}}$ are the computed backscattering coefficients derived from the Sentinel-1A image and simulated values by modified WCM at VV polarization, respectively. The model parameters of modified WCM are shown in Table 3. 


\begin{tabular}{|c|c|c|}
\hline \multirow{3}{*}{$\begin{array}{c}\text { Model } \\
\text { Parameters }\end{array}$} & \multicolumn{2}{|c|}{ Vegetation Descriptor } \\
\cline { 2 - 3 } & $\mathbf{V}_{\mathbf{1}}=\mathbf{V}_{\mathbf{2}}=\mathbf{L A I}$ & $\mathbf{V}_{\mathbf{1}}=\mathbf{V}_{\mathbf{2}}=\mathbf{L W A I}$ \\
\cline { 2 - 3 } & VV -polarization & VV- polarization \\
\hline $\mathrm{A}$ & 0.091 & 0.253 \\
\hline $\mathrm{E}$ & 1.568 & 2.462 \\
\hline $\mathrm{B}$ & 0.217 & 0.288 \\
\hline $\mathrm{C}$ & -13.87 & -13.87 \\
\hline $\mathrm{D}$ & 26.12 & 26.12 \\
\hline
\end{tabular}

Table 3.Model parameters of modified WCM at VV polarization

\section{RESULTS AND DISCUSSION}

In order to verify the potential of modified WCM, sixty samples of the observed data were randomly chosen to compute the model parameters and rest were used to validate the developed model.

\subsection{Simulation of $\sigma^{0}(\mathrm{~dB})$ based on C-band Sentinel -1A data.}

The modified WCM has a significant potential to correlates the vegetation factors with satellite observation data. Figures. 3 shows the relationship between simulated $\sigma^{0}(\mathrm{~dB})$ from modified WCM and computed from Sentinel-1A satellite data. The simulated $\sigma^{0}(\mathrm{~dB})$ with vegetation descriptor $\left(\mathrm{V}_{1}=\mathrm{V}_{2}\right)$ LAI was shown high $\mathrm{R}^{2}(96.35 \%)$ and low RMSE $(0.152 \mathrm{~dB})$. LAI is one of the key parameter of vegetation which relates good consistency with synthetic aperture radar (SAR) data observation like $\sigma^{0}(\mathrm{~dB})$ at $\mathrm{VV}$ polarization (Bousbih et al. 2017, Svoray et al. 2002, Beriaux et al. 2013).

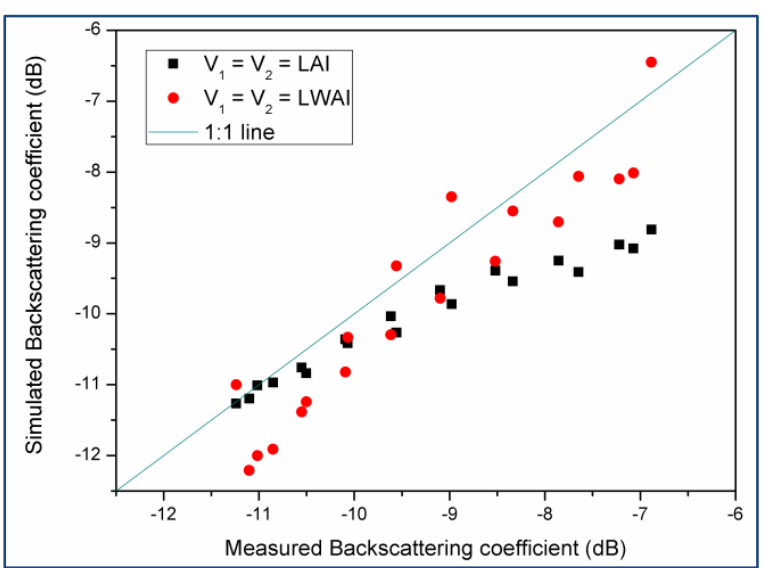

Figure 3.Comparison between measured $\sigma^{0}(\mathrm{~dB})$ from Sentinel -1A image and simulated $\sigma^{0}(\mathrm{~dB})$ through modified WCM at VV polarization
The simulated $\sigma^{0}(\mathrm{~dB})$ with LWAI shows good correlation with measured data, but it was found relatively lower than that of LAI at VV polarization. The performance indices are shown in Table 4, which describes the potential of modified model due to incorporation of vegetation fraction $\left(f_{\text {veg }}\right)$ derived from Landsat -8 data.

\begin{tabular}{|c|c|c|}
\hline \multirow{2}{*}{} & \multicolumn{2}{|c|}{ Backscattering coefficient $\left(\boldsymbol{\sigma}^{\mathbf{0}}\right)$} \\
\cline { 2 - 3 } & $\mathbf{V}_{\mathbf{1}}=\mathbf{V}_{\mathbf{2}}=\mathbf{L A I}$ & $\mathbf{V}_{\mathbf{1}}=\mathbf{V}_{\mathbf{2}}=\mathbf{L W A I}$ \\
\hline Polarization & $\mathrm{VV}$ & $\mathrm{VV}$ \\
\hline $\mathrm{R}^{2}(\%)$ & 96.35 & 89.21 \\
\hline $\mathrm{RMSE}(\mathrm{dB})$ & 0.152 & 0.538 \\
\hline
\end{tabular}

Table 4.Performance indices for estimation of $\sigma^{0}(\mathrm{~dB})$ with different vegetation descriptor

\subsection{Estimation of LAI and LWAI}

The biophysical parameter estimation was done by numerical inversion of modified WCM followed by LUT algorithm. The modelled LAI and LWAI computed from modified WCM were further compared with observed ground truth samples. Figures 4 and 5 showed very good relationship between the estimated values and observed values of LAI and LWAI indicated by getting high $\mathrm{R}^{2}$ $(83.08 \%)$ and low RMSE $\left(0.502 \mathrm{~m}^{2} / \mathrm{m}^{2}\right.$. The estimation of LWAI by this model was found good, however poor performance indices $\left(\mathrm{R}^{2}=76.0 \%\right.$ and $\mathrm{RMSE}=0.560$ $\mathrm{m}^{2} / \mathrm{m}^{2}$ ) were found in comparison to that of LAI estimation. The consistency of LAI inversion in this model was more accurate than LWAI at VV polarization for wheat crop. Therefore, LAI directly quantifies the crop growth activities with SAR signal which play the crucial role for the estimation of LAI more accurately.

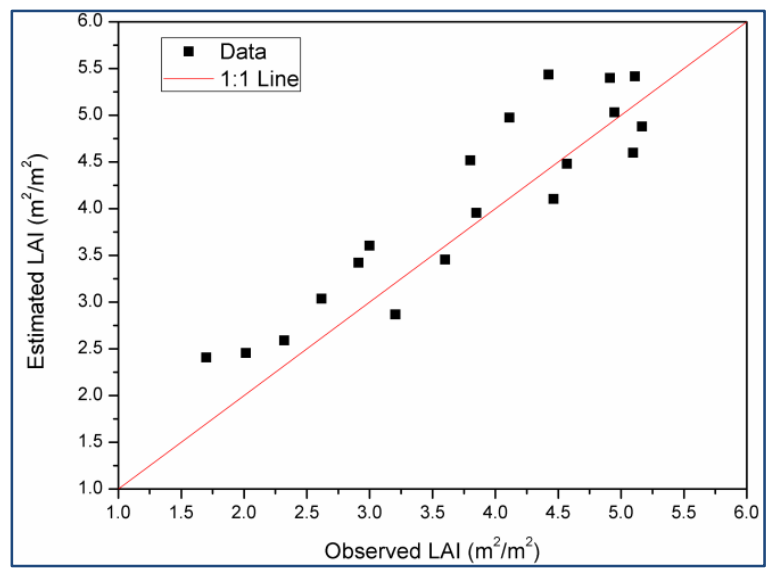

Figure 4.Comparison between observed and estimated values of LAI by modified WCM 


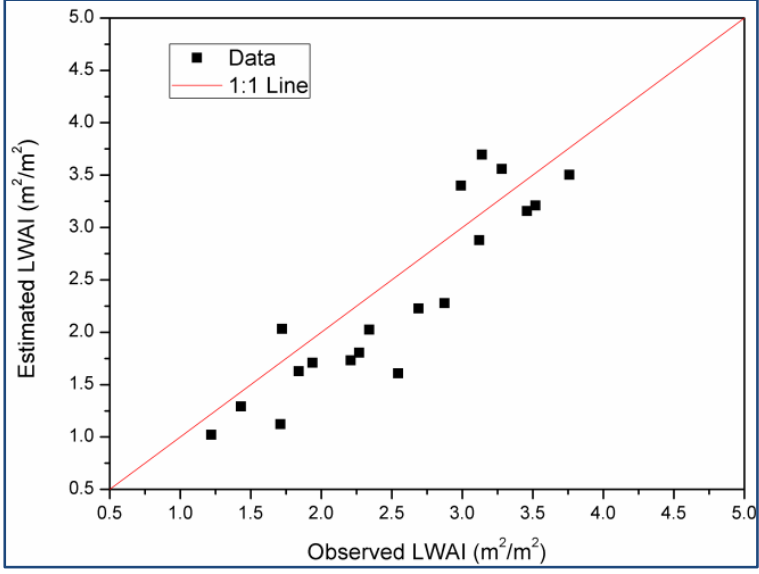

Figure 5.Comparison between observed and estimated values of LWAI by modified WCM

However, the performance accuracy of modified WCM is evaluated by statistical indices such as $\mathrm{R}^{2}$ and RMSE. This is necessary requirement to assess the potential of developed model for accurate estimation of crop growth variables. Table 5 shows performance indices of estimation of LAI and LWAI for wheat crop at VV polarization.

\begin{tabular}{|c|c|c|}
\hline \multirow{2}{*}{} & \multicolumn{2}{|c|}{ Biophysical Parameters } \\
\cline { 2 - 3 } & LAI & LWAI \\
\hline Polarization & VV & VV \\
\hline $\mathrm{R}^{2}(\%)$ & 83.08 & 76.0 \\
\hline $\mathrm{RMSE}\left(\mathrm{m}^{2} / \mathrm{m}^{2}\right)$ & 0.502 & 0.560 \\
\hline
\end{tabular}

Table 5.Performance indices for estimation of LAI and LWAI using modified WCM

\section{CONCLUSION}

The present approach shows high potential of inversion of the modified WCM model by incorporating vegetation fraction derived from the optical data for the accurate estimation of LAI and LWAI of wheat crop. The C-band SAR data at VV- polarization was found more useful for the accurate estimation of LAI and LWAI for wheat crop indicated by getting high values $\mathrm{R}^{2}$ such as $83.08 \%$ and $76 \%$, respectively. Further, the integration of Sentinel-1A with Landsat- 8 satellite data provided the significant improvement in the estimation accuracy of LAI and LWAI.

\section{ACKNOWLEDGEMENT}

The authors would like to thank the European Space Agency (ESA) and NASA for providing free access to the Sentinel-1A and Landsat- 8 satellite data, respectively.

\section{REFERENCES}

Beer, C., Reichstein, M., Tomelleri, E., Ciais, P., Jung, M., Carvalhais, N., Rödenbeck, C., Arain, M.A., Baldocchi, D., Bonan, G.B. Terrestrial Gross Carbon Dioxide Uptake: Global Distribution and Covariation with Climate. Science 2010, 329, 834-838.

Beriaux Emilie, Lucau-Danila Cozmin, Auquiere Eric, Defourny Pierre, 2013. Multiyear independent validation of the water cloud model for retrieving maize leaf area index from SAR time series. International Journal of Remote Sensing, Vol. 34, No. 12, 4156-4181.

Bruckler L, Witono H, Stengel P. 1988. Near surface soil moisture estimation from microwave measurements. Remote Sens. Environ. 26:101-121.

Bousbih Safa, Zribi Mehrez, Lili-Chabaane Zohra, Baghdadi Nicolas, Hajj Mohammad El, Gao Qi, Mougenot Bernard. Potential of Sentinel-1 Radar Data for the Assessment of Soil and Cereal Cover Parameters. Sensors 2017, 17, 2617.

Dabrowska-Zielinska K, Inoue Y, Kowalik W, Gruszczynska M. 2007.Inferring the effect of plant and soil variables on $\mathrm{C}$ - and L-band SAR backscatter over agricultural fields, based on model analysis. Advances in Space Research 39: 139-148.

Kumar, K. Prasad, Rao, Hari Prasad Suryanarayana and Arora, M. K., 2015. Study of water cloud model vegetation descriptors in estimating soil moisture in Solani catchment. Hydrological. Sci. J., 29, 2137-2148

Kumar, K., Prasad, K. S. Hari, and Arora, M. K., Apr. 2012.Estimation of water cloud model vegetation parameters using a genetic algorithm, Hydrological. Sci. J., vol. 57 , no. 4 , pp. 776-789.

Kumar P., Prasad R., Choudhary A., Gupta D.K., Mishra V.N., Vishwakarma A.K., Singh A. K., Srivastava P. K.. 2018 Comprehensive evaluation of soil moisture retrieval models under different crop cover types using C-band synthetic aperture radar data. Geocarto Int, https://doi.org/10.1080/10106049.2018.1464601

Morvan AL, Zribi M, Baghdadi N, Chanzy A. 2008. Soil moisture profile effect on radar signal measurement. Sensors.8: 256-270.

Prasad R., January 2011, Estimation of kidney bean crop variables using ground-based scatterometer data at 9.89 GHz. International Journal of Remote Sensing, Vol. 32, No. 1, 31-48.

Prevot, L. I. Champion, and Guyot, G., Dec.1993. Estimating surface soil moisture and leaf area index of a wheat canopy using a dual-frequency ( $\mathrm{C}$ and $\mathrm{X}$ bands) 
scatterometer, Remote Sens. Environ., vol. 46, no. 3, pp. $331-339$.

Raich, J.W., Schlesinger, W.H. The global carbon dioxide flux in soil respiration and its relationship to vegetation and climate. Tellus B 1992, 44, 81-99.

Svoray T. \& Shoshany M.,2002. SAR-based estimation of areal aboveground biomass (AAB) of herbaceous vegetation in the semi-arid zone: A modification of the water-cloud model. International Journal of Remote Sensing, vol. 23, no. 19, 4089-4100.

Ulaby, F. T., Allen, C. T., Eger, G. III, and Kanemasu, E., Jan.1984.Relating the microwave backscattering coefficient to leaf area index, Remote Sens. Environ., vol. 14, no. 1, pp. 113-133.

Ulaby, F.T., Moore, R.K., Fung, A.K., 1982. Microwave Remote Sensing Active and Passive-Volume II: Radar Remote Sensing and Surface Scattering and Enission Theory. Reading, MA: Addison-Wesley

Ulaby, F.T., Moore, R.K., Fung, A.K., 1981b. Microwave remote sensing: from theory to applications. Artech House. 